\title{
CONSIDERAÇÕES SOBRE O SISTEMA JURÍDICO
}

\section{Eder Dion de Paula Costa}

Doutorando em Direito na UFPR, Professor da FURG/RS.

\begin{abstract}
SUMÁRIO: Introdução; $1 \mathrm{O}$ ordenamento jurídico; 2 A unidade do ordenamento jurídico; 3 A coerência do ordenamento jurídico; $4 \mathrm{O}$ sistema jurídico; $5 \mathrm{~A}$ interpretação do direito; 6 Antinomias jurídicas; 7 Lacunas do direito; Considerações finais; Referências bibliográficas.
\end{abstract}

\section{INTRODUÇÃO}

A proposta do presente trabalho é a de apresentar algumas considerações sobre o sistema jurídico. Nesse sentido, procuramos, num primeiro momento, trabalhar o conceito de ordenamento jurídico, sendo utilizado como parâmetro os estudos elaborados por NORBERTO BOBBIO em sua Teoria do ordenamento jurídico. Assim, visamos a explicitar o desenvolvimento dessa teoria, que tem como ponto de partida a compreensão do direito não a partir da norma, mas sim do conjunto de regras que formam um determinado ordenamento jurídico.

O ordenamento jurídico de BOBBIO, baseado nas concepções de HANS KELSEN, apresenta os aspectos fundamentais de unidade e coerência do ordenamento jurídico, em que resume estes como uma unidade sistemática.

Detemo-nos, igualmente, na construção de sistema jurídico elaborado por CLAUS-WILHELM CANARIS, discípulo de KARL LARENZ. Na esteira de CANARIS, valemo-nos dos estudos do Prof. JUAREZ FREITAS em sua obra a Interpretação sistemática do direito. Apresentamos de forma sintética os métodos de interpretação do direito, os quais se justificam em função das possibilidades de solucionar as chamadas antinomias jurídicas e as lacunas do direito, conforme o verificado por FREITAS.

Na parte referente às antinomias jurídicas e às lacunas do direito, propomo-nos a estabelecer um estudo das propostas de solução apresentadas na obra de NORBERTO BOBBIO e, igualmente, no trabalho realizado pelo Prof. JUAREZ FREITAS, o qual se ancorou com propriedade na obra de CANARIS, Pensamento sistemático e conceito de sistema na ciência do direito.

\section{O ORDENAMENTO JURÍDICO}

O jurista italiano NORBERTO BOBBIO trabalha com o conceito de ordenamento jurídico, o qual é para ele um conjunto ou complexo de normas. Assim, tem a compreensão de que as normas não existem isoladamente, estando em um contexto no qual ocorrem relações particulares entre si. 
A proposta de BOBBIO é a de realizar um estudo aprofundado das normas em seu conjunto, daí a compreensão de que, através de um ordenamento que possua uma determinada coerência intrínseca, seja possível verificar os problemas gerais do direito, visto que até então a análise era realizada em função da norma jurídica propriamente dita.

BOBBIO, ao estabelecer a definição de direito, analisa o conceito de norma jurídica, em que são observados os aspectos da exterioridade e da institucionalização, e, assim, é possível dizer que a norma jurídica é aquela "cuja execução é garantida por uma sanção externa e institucionalizada". ${ }^{1}$ Partindo dessa análise, verifica que a sanção jurídica deve ser institucionalizada, o que demanda um certo grau de organização, de complexidade. Assim, ao se ter a noção de sanção organizada, é curial que se procure o caracter distintivo do direito num complexo de normas e não em um elemento da norma. Dois aspectos são fundamentais na teoria de NORBERTO BOBBIO, os quais dizem respeito à unidade e à coerência do ordenamento jurídico.

\section{A UNIDADE DO ORDENAMENTO JURÍDICO}

No que tange ao estabelecimento da unidade do ordenamento jurídico, verifica alguns aspectos que possam caracterizar essa condição, como é caso das chamadas fontes delegadas e fontes reconhecidas. BOBBIO apresenta essas chamadas fontes indiretas, visto que é crível em se admitir que "a complexidade de um ordenamento jurídico deriva do fato que a necessidade de regras de conduta numa sociedade é tão grande que não existe nenhum poder (órgão) em condições de satisfazê-la sozinho". Nesse sentido, o poder busca alguns expedientes para conseguir solucionar esta dificuldade, e isso se verifica na recepção de normas já feitas, produzidas por ordenamentos diversos e precedentes, bem como na delegação do poder de produzir normas jurídicas a poderes ou órgãos inferiores.

Exemplo de fonte reconhecida para BOBBIO é o costume, o qual é recepcionado pelo ordenamento em decorrência de situações ou matérias não reguladas. Como exemplo de fonte delegada, tem-se o regulamento com relação à lei, a qual é geralmente confiada ao Poder Executivo, em que uma de suas atribuições é a de integrar leis muito genéricas, que contêm somente diretrizes de princípio e não poderiam ser aplicadas sem serem ulteriormente especificadas.

A unidade do ordenamento jurídico é característica fácil de se observar quando da existência de um ordenamento simples, em que todas as normas resultam de uma única fonte. No entanto, quando se trata de um ordenamento jurídico complexo, tem-se situação em que as normas de um ordenamento não estão todas no mesmo plano. Neste caso, BOBBIO utiliza-se da proposição elaborada por KELSEN em que evidencia a construção escalonada do ordenamento. Assim, a base dessa proposição é de que existem normas inferiores e superiores, em que as primeiras dependem das segundas, e isso de 
forma escalonada e hierarquizada até o ponto da existência de uma norma fundamental, que se encontra acima de todas as demais, sendo o termo unificador das normas que compõem um ordenamento jurídico.

Verifica BOBBIO que a eficácia de uma norma decorre de esta ser válida, e esta para ser válida deve pertencer a um ordenamento jurídico. Integrando a norma o referido ordenamento, deve-se perscrutar em que momento no ordenamento é dado essa condição de validade. Assim, é possível chegar à razão última do ordenamento, ou seja, à sua norma fundamental, da qual todas as demais emanam.

A norma fundamental que se compreende em um ordenamento é a Constituição. No entanto, essa Constituição como uma outra norma ordinária depende de um poder normativo da qual se originou. A Constituição decorre de um poder originário, da qual é o pressuposto de sua existência uma norma que atribua ao poder constituinte a faculdade de produzir normas jurídicas. BOBBIO diz que a norma que dá vida ao poder originário é a norma fundamental, tanto que, "enquanto, por um lado, atribui aos órgãos constitucionais poder de fixar normas válidas, impõe a todos aqueles aos quais se referem às normas constitucionais o dever de obedecê-las". ${ }^{2}$

A validade da norma pertencente a um ordenamento jurídico é verificada quando da possibilidade de ser reinserida na norma fundamental, em um ou mais graus no escalonamento hierárquico do ordenamento, podendo chegar em última instância até a norma fundamental. Assim chegando, é de se perguntar qual o fundamento que justifica a norma fundamental, a sua razão de ser. BOBBIO tem respondido que "ela não tem fundamento, porque, se tivesse, não seria mais a norma fundamental, mas haveria outra norma superior, da qual ela dependeria".

BOBBIO expressa que, para se compreender qual o fundamento da norma fundamental de um ordenamento jurídico positivo, é necessário que se transcenda a um ordenamento mais amplo, que esteja fora desse sistema. Assim, apresenta as várias concepções:

- o modelo absolutista, do qual todo o poder emana de Deus, e, nesse sentido, deve-se obedecer ao poder constituinte que recebeu de Deus a autorização para assim proceder;

- a lei natural, da qual decorre o dever de obedecer ao poder constituinte. Assim, segue a teoria da obediência, na qual por uma razão natural, devemos obedecer aos governantes;

- o contrato social, acordo originário entre os membros de uma determinada sociedade e aqueles aos quais é confiado o poder.

Essas concepções justificam a existência de uma norma que fundamenta a norma fundamental, no entanto, é de se perquirir qual o conteúdo dessa norma. Compreendendo 
que se funda no contrato social, que decorre da vontade, tal como se vê em ROUSSEAU, "em que o contrato só constitui a sociedade, a qual deve servir à plena expansão da personalidade do indivíduo. A sociedade e o povo nunca podem perder sua soberania, a qual pertence ao povo e só ao povo. Por conseguinte o povo nunca deve criar um Estado distinto ou separado de si mesmo. O único órgão soberano é a assembléia, e nesta é que se expressa a soberania". ${ }^{4}$

ROUSSEAU, ao estabelecer que o poder soberano decorre da assembléia, não minimiza o aspecto de que este poder originário seja o resultado do conjunto das forças políticas que num determinado momento histórico tomaram o domínio e instauraram um novo ordenamento jurídico. Assim, é plausível a constatação da existência de uma força dominante que não seja necessariamente decorrente da força física, mas de um poder político que se sobrepõe. BOBBIO expressa "que quando a norma fundamental diz que se deve obedecer ao poder originário, não deve absolutamente ser interpretada no sentido de que devemos nos submeter à violência, mas no sentido de que devemos nos submeter àqueles que têm o poder coercitivo". Assim, completa que os detentores do poder são aqueles que têm a força necessária para fazer respeitar as normas que deles emanam, sendo a força um instrumento necessário do poder.

O que BOBBIO tenta expor, e a consideração que se pode fazer quanto a sua assertiva, a qual é justificada, é de que não se está a falar de um direito justo, de um direito ideal, de como ele deveria ser, mas que se trata do direito positivo, de como ele é. Neste aspecto, não há meias palavras ou a ilusão de uma proposta teórica que solucione toda a problemática do direito, em que se identificar com o ideal de justiça. Assim, BOBBIO diz que a definição do direito que adota em sua teoria do ordenamento jurídico não coincide com a de justiça, em que o direito é um conjunto de regras com eficácia reforçada, o que significaria que é impensável um ordenamento jurídico sem o exercício da força, ou melhor, sem um poder. Nesse diapasão, o direito é a expressão dos mais fortes e não dos mais justos, sendo que seria bem melhor se os mais fortes também fossem os mais justos.

BOBBIO tem a preocupação de estabelecer constantemente que a juridicidade de uma norma está em ela pertencer a um ordenamento jurídico e não no fato de identificar o seu conteúdo. Assim, a definição do direito como um conjunto de regras para o exercício da força é uma definição que pode estar classificada entre outras a respeito do conteúdo da norma, mas não explicita a razão de seu pertencimento ao ordenamento jurídico. As regras que têm o fim de estabelecer o exercício da força num ordenamento jurídico servem para organizar a sanção; no entanto, o objetivo do legislador não é o de organizar a força, mas o de organizar a sociedade mediante a força. Nesse aspecto, BOBBIO justifica a juridicidade do ordenamento, visto este em seu conjunto, quando se vêm formando regras pelo uso da força, ou seja, passa-se do uso indiscriminado ao uso limitado e controlado da força. 


\section{A COERÊNCIA DO ORDENAMENTO JURÍDICO}

A unidade do ordenamento jurídico por si só não permite que se tenha um sistema jurídico, devendo ser verificado, segundo o conceito de BOBBIO, que sistema é uma totalidade ordenada, um conjunto de entes entre os quais existe uma certa ordem. Assim, as relações dos entes com o todo não devem ocorrer tão-somente em função da unidade, mas também deve existir uma coerência entre si. O ordenamento jurídico deve ser uma unidade sistemática.

BOBBIO analisa três diferentes significados de sistema. O primeiro corresponde à expressão sistema dedutivo, em que dado ordenamento é um sistema, enquanto todas as normas jurídicas daquele ordenamento são deriváveis de alguns princípios gerais, considerados da mesma maneira que os postulados de um sistema científico. Nesse sentido, é interessante a referência que BOBBIO faz ao texto de LEIBNIZ: "De qualquer definição podem-se tirar conseqüências seguras, empregando as incontestáveis regras da lógica. Isso é precisamente o que se faz construindo as ciências necessárias e demonstrativas, que não dependem dos fatos, mas unicamente da razão, como a lógica, a metafísica, a geometria, a ciência do movimento, a ciência do direito, as quais não são de modo nenhum fundadas na experiência e nos fatos, mas servem para dar razão dos fatos e regulá-los por antecipação: isso valeria para o direito ainda que não houvesse no mundo uma só lei".

O segundo significado de sistema é encontrado na ciência do direito moderno, através de SAVIGNY, no seu conhecido sistema do direito romano atual. BOBBIO expressa que muitos juristas são da opinião de que a ciência jurídica moderna nasceu da passagem da jurisprudência exegética à jurisprudência sistemática, ou seja, a jurisprudência se elevou ao nível de ciência tornando-se "sistemática". O termo sistema nessa concepção é usado para indicar um ordenamento da matéria, realizado através do processo indutivo, partindo do conteúdo das simples normas com a finalidade de construir conceitos sempre mais gerais e classificações ou divisões da matéria inteira. Assim, tem-se por conseqüência dessas operações o ordenamento do material jurídico do mesmo modo que as classificações do zoólogo dão um ordenamento ao reino animal.

BOBBIO analisa um terceiro significado de sistema jurídico, o qual mais the impressiona, tendo como característica o aspecto de que o ordenamento jurídico somente se constitui em sistema, porque não podem coexistir nele normas incompatíveis. Existe nesse modelo de sistema o princípio que exclui a incompatibilidade das normas, de tal forma que no conflito entre duas normas, uma delas ou as duas devem ser eliminadas.

A proposição de sistema jurídico que apresenta o princípio que exclui a incompatibilidade é de possibilitar a manutenção do sistema, de tal forma que, se for necessário excluir uma ou as duas normas, isso não redundará na queda do sistema como um todo. O princípio da incompatibilidade das normas não pressupõe que estas tenham que se encaixar de forma perfeita, visto que pode ocorrer a divergência de significado entre uma norma e outra; porém, para permanecerem no ordenamento sistemático, terão que ser compatíveis. Um exemplo de BOBBIO elucida bem esta proposição: "O quadro é negro" e "O café é amargo". Vistos esses dois enunciados, 
pode-se dizer que apresentam sentidos diferentes, no entanto, são plenamente compatíveis.

\section{O SISTEMA JURÍDICO}

A hermenêutica jurídica, enquanto ciência que se preocupa com a interpretação do direito, tem como objeto de estudo o sistema jurídico. Certamente que não se pode ter a noção de um sistema, segundo o qual as normas jurídicas guardariam entre si relação apenas de forma, destituída de conteúdo.

Um sistema jurídico que seja apenas normativo e isento de valores não mais se coaduna com a realidade em que vivemos. Um sistema fechado e que tenha por finalidade o simples estabelecimento de regras de conduta da sociedade, sem ater-se aos princípios e valores que estejam intrínsecos, pode muito bem representar um Estado em que o poder esteja enfeixado nas mãos de um tirano ou de um déspota. Neste caso, em termos de política jurídica, talvez seja a única garantia que se possa permitir à sociedade, ou seja, a defesa do meramente legal, sob pena de transformar-se em pura barbárie.

A existência de um sistema fechado e hermético, que pretenda ser a ordem jurídica posta, pressupõe, inexoravelmente, que parte da sociedade crie um ordenamento jurídico alternativo ou paralelo. Isso ocorre em razão de que parte do tecido social encontra-se alijado do acesso à justiça, ou seja, seus anseios, aspirações e valores não são apreciados pelo Poder Judiciário. A sociedade humana tem historicamente reagido às imposições de sistemas que se prestem à clausura, chegando muitas vezes à alternativa revolucionária de derrubada do sistema jurídico e político. PAULO BONAVIDES, ao abordar sobre a origem e a causa das revoluções, diz que esta "se prenderia a uma lenta acumulação de descontentamentos e impugnações da ordem de valores implantados ou impostos até a chegada de um momento crítico de deterioração final". 5

Numa sociedade em que se pretenda um Estado Democrático de Direito só é possível pensar em sistema jurídico enquanto um sistema aberto e fragmentário, que vai superando uma estrutura estática, dando dinamicidade a um sistema que se propõe a regular a ordem social. Nesse sentido, o exposto por KARL LARENZ" de que "o sistema interno não é, como se depreende do que foi dito, um sistema fechado, mas um sistema aberto, no sentido de que são possíveis, tanto mutações na espécie de jogo concertado dos princípios, do seu alcance e limitação recíproca, como também a descoberta de novos princípios; seja em virtude de alterações da legislação, seja em virtude de novos conhecimentos da ciência do direito ou modificações na jurisprudência". LARENZ, citando CANARIS, diz que "o sistema, como unidade de sentido de uma ordem jurídica concreta, comunga do modo de ser desta, quer dizer, assim como não é estático, mas dinâmico, apresenta, portanto, a estrutura da historicidade". ${ }^{7}$

5 BONAVIDES, Paulo. In: Ciência política. 7. ed. Rio de Janeiro: Forense, p. 517.

6 LARENZ, Karl. In: Metodologia da ciência do direito. Trad. José Lamego. Lisboa: Fundação Calouste Gulbenkian, p. 592.

7 Vide LARENZ, Karl. Ob. cit., p. 592. 
O ordenamento jurídico, enquanto sistema, conforme análise já efetuada, deve ter unidade interior e coerência. Assim, é que NORBERTO BOBBIO estabelece por unidade quando "se pressupõe como base do ordenamento uma norma fundamental com a qual se possam, direta ou indiretamente, relacionar todas as normas do ordenamento". ${ }^{8}$ Certamente que tal relação não é suficiente para formar um sistema, "é necessário que os entes que a constituem não estejam somente em relacionamento com o todo, mas também num relacionamento de coerência entre si"..

O novo modelo de sistema jurídico é aquele que está permeado de valores e que tem como base fundamental a Constituição. Assim, é possível vislumbrar a perspectiva renovadora do novo modelo de sistema jurídico a qual o jurista JUAREZ FREITAS tão bem expõe "como sendo uma rede axiológica e hierarquizada de princípios gerais e tópicos, de normas e de valores jurídicos cuja função é a de, evitando ou superando antinomias, dar cumprimento aos princípios e objetivos fundamentais do Estado Democrático de Direito, assim como se encontram consubstanciados, expressa ou implicitamente, na Lei Maior". ${ }^{10}$

$\mathrm{O}$ ordenamento jurídico tem que ser entendido como um sistema aberto e completável, cabendo ao hermeneuta a responsabilidade de bem interpretá-lo a fim de dar cumprimento aos seus objetivos fundamentais.

\section{A INTERPRETAÇÃO DO DIREITO}

Antes de conceituarmos o que seja interpretação, é necessário sabermos por que ela desempenha um papel importante na ciência do direito. Vivemos num País que tem a sua tradição jurídica baseada no sistema romano-germânico. Nesse sentido, toda a nossa ordem jurídica tem como premissa fundamental o direito posto, escrito, positivado.

A representação do direito positivo é a norma jurídica e, como tal, tem o objetivo de ser uma norma de conduta, no sentido de que seu escopo direto ou indireto é dirigir o comportamento dos particulares, das comunidades, dos governantes e funcionários no seio do Estado e do mesmo Estado na ordem internacional. A norma jurídica é abstrata, uma vez que se dirige a todos. Assim, para a sua aplicação no caso concreto se faz necessária a sua interpretação. DEGNI, citado por MARIA HELENA DINIZ, ${ }^{11}$ afirma que "A clareza de um texto legal é coisa relativa. Uma mesma disposição pode ser clara em sua aplicação aos casos mais imediatos e pode ser duvidoso quando se aplica a outras relações que nela possam enquadrar e às quais não se refere diretamente, e a outras questões que, na prática, em sua atuação, podem sempre surgir. Uma disposição

8 BOBBIO, Norberto. Teoria do ordenamento jurídico. Trad. Cláudio de Cicco e Maria Celeste C. J. Santos. 4. ed. Brasília: Universidade de Brasília, 1994, p. 71.

9 Idem, ob. cit, p. 71.

10 Vide FREITAS, Juarez. Ob. cit., p. 44.

11 DINIZ, Maria Helena. In: Compêndio de introdução à ciência do direito. 7. ed. São Paulo: Saraiva, 1995 , p. 381 
poderá parecer clara a quem a examinar superficialmente, ao passo que se revelará tal a quem a considerar nos seus fins, nos seus precedentes históricos, nas suas conexões com todos os elementos sociais que agem sobre a vida do direito na sua aplicação a relações que, como produto de novas exigências e condições, não poderiam ser consideradas, ao tempo da formação da lei, na sua conexão com o sistema geral do direito positivo vigente".

Verificada a importância da interpretação na aplicação do direito, uma vez que a norma por si só não é suficiente para a solução do caso concreto, isso em razão de ser abstrata, é necessário que o intérprete utilize-se de algumas técnicas que poderão orientálo em sua tarefa. Entre tais técnicas, temos a interpretação gramatical ou literal, lógica, sistemática, histórica e sociológica ou teleológica.

A interpretação gramatical é aquela em que o hermeneuta busca o sentido literal do texto normativo, ou seja, os significados que possa ter, marcando o limite da interpretação, e o aplicador opta ou decide por um dos diferentes sentidos admissíveis.

No processo lógico de interpretação, o hermeneuta procura desvendar o sentido lógico e o alcance da norma, estudando-a por meio de raciocínios lógicos, analisando os períodos da lei e combinando-os entre si, com o escopo de atingir perfeita compatibilidade.

O processo sistemático é o que considera o sistema em que se insere a norma, relacionando-a com outras normas concernentes ao mesmo objeto. É tarefa do hermeneuta, ao utilizar o processo sistemático, relacionar as normas entre si, procurando vislumbrar-lhes o sentido e o alcance.

A interpretação histórica baseia-se na averiguação dos antecedentes da norma. Busca fazer uma análise do histórico do processo legislativo, desde o projeto de lei, sua justificativa ou exposição de motivos, emendas, aprovação e promulgação, ou as circunstâncias fáticas que a precederem e que lhe deram origem, às causas ou necessidades que induziram o órgão a elaborá-la, ou seja, às condições culturais ou psicológicas sob as quais o preceito normativo surgiu.

A interpretação sociológica ou teleológica procura estabelecer qual a finalidade da norma, partindo inicialmente de identificar a razão do preceito normativo. O intérprete deve ter a compreensão de que a norma se destina a um fim social, procurando, assim, a partir deste pressuposto, o sentido e o alcance da norma.

A utilização de somente uma ou outra técnica de interpretação não tem sido suficiente para que se tenha interpretação e aplicação justas do direito ao caso concreto. É necessário que se lance mão de todas as técnicas disponíveis, visto que estas "são apenas momentos de uma mesma atividade cognitiva, construtiva e relacional". Assim, é de compreender-se que interpretar o direito é necessariamente sistematizar aquilo que parece fragmentário e isolado.

Ao compreendermos o direito como um sistema, temos tido claro que a sua interpretação há de ser sistemática, e, para tal, é mister que se conceitue o que seja a interpretação sistemática do direito. Essa tem sido a grande preocupação do jurista 
JUAREZ FREITAS, que procura dar uma ótica ampliada ao tema, afirmando que "a interpretação sistemática deve ser definida como uma operação que consiste em atribuir a melhor significação, dentre várias possíveis, aos princípios, às normas e aos valores jurídicos, hierarquizando-os num todo aberto, fixando-lhes o alcance e superando antinomias, a partir da conformação teleológica, tendo em vista solucionar os casos concretos". ${ }^{12}$

Esse novo conceito de interpretação sistemática tem um aspecto fundamental, que é o metacritério da hierarquização axiológica. Interpretar consiste sempre em hierarquizar. O exegeta, para uma perfeita interpretação sistemática, tem necessariamente que hierarquizar seja em relação às normas, em inferior ou superior, geral ou especial, seja em relação aos princípios e aos valores jurídicos. A hierarquização de princípios e valores visa a superar as antinomias, e o parâmetro pela qual o hermeneuta deve se guiar é a Constituição. Nesta, o intérprete busca encontrar os valores maiores de uma sociedade, os quais estão disseminados em normas e princípios do sistema jurídico. Vimos, assim, que o sistema está impregnado de valores, ou melhor, não há norma ou princípio que não tenha valor.

O princípio da hierarquização axiológica é, por assim dizer, um superprincípio ou metaprincípio que "faz às vezes de um imperativo principiológico que imprime unidade sistemática aos fins jurídicos". ${ }^{13}$ A importância maior que verificamos nesse metacritério é o de superar as antinomias e as contradições que possam ocorrer no interior do sistema. JUAREZ FREITAS bem esclarece esse superprincípio ao conceituálo como "o metacritério que ordena, diante inclusive de antinomias no plano dos critérios, a prevalência do princípio axiologicamente superior, ou da norma axiologicamente superior em relação às demais, visando-se a uma exegese que impeça a autocontradição do sistema conforme a Constituição e que resguarde a unidade sintética dos seus múltiplos comandos". ${ }^{14}$

\section{ANTINOMIAS JURÍDICAS}

Dentro de um sistema jurídico, notadamente o de nossa tradição romanística, o que mais tem trazido inquietação ao hermeneuta é o que concerne à situação das normas incompatíveis entre si, a qual tem a denominação própria de antinomia. NORBERTO BOBBIO define antinomia jurídica "como aquela situação que se verifica entre duas normas incompatíveis, pertencentes ao mesmo ordenamento e tendo o mesmo âmbito de validade." ${ }^{15}$ Assim, a antinomia dá-se dentro da ordem jurídica positiva, o que se tem chamado até então de sistema jurídico. Por validade, diz que são aquelas que ocorrem dentro de um âmbito temporal, espacial, pessoal ou material, não caracterizando antinomia quando não coincidirem com âmbito de incidência.

12 FREITAS, Juarez. Ob. cit., p. 54

13 FREITAS, Juarez. Ob. cit., p. 80.

14 Idem, ob. cit., p. 81 .

15 BOBBIO, Norberto. Ob. cit., p. 88 
O sistema jurídico positivo possui critérios para a solução das antinomias jurídicas, para a qual BOBBIO explicita três regras fundamentais:

a) critério cronológico, chamado também de lex posterior, é aquele com base no qual, entre duas normas incompatíveis, prevalece a norma posterior: lex posterior derogat priori;

b) critério hierárquico, chamado também de lex superior, é aquele pelo qual, entre duas normas incompatíveis, prevalece a hierarquicamente superior: lex superior derogat inferiori. Para BOBBIO, as normas superiores podem revogar as inferiores, mas as inferiores não podem revogar as superiores. Alerta, como conseqüência da hierarquia normativa, que a inferioridade de uma norma em relação a outra consiste na menor força do seu poder normativo;

c) critério da especialidade, dito justamente da lex specialis, é aquele pelo qual, de duas normas incompatíveis, uma geral e uma especial (ou excepcional), prevalece a segunda: lex specialis derogat generali.

NORBERTO BOBBIO, ao abordar os critérios de solução das antinomias, deixa claro que esses igualmente não são suficientes para debelar todas as possibilidades de conflitos. Coloca o exemplo que pode ocorrer da antinomia entre duas normas que sejam ao mesmo tempo contemporâneas, do mesmo nível e ambas gerais. Não serve o critério cronológico, porque são estabelecidas ao mesmo tempo; o hierárquico, porque são todas leis ordinárias; e o da especialidade, porque não trata de antinomia total-total e sim total-parcial, em que o conflito é em aspecto específico.

BOBBIO apresenta um quarto critério para a solução das antinomias, o qual ressalva, porém, a necessidade de "uma confirmação numa paciente análise das decisões dos magistrados". ${ }^{16}$ Trata do critério da forma da norma, qual seja em relação às normas imperativas, proibitivas e permissivas. Nesse caso, a antinomia seria solvida pela prevalência da norma permissiva em relação à norma proibitiva na qual diz "que é o de dar preponderância, em caso de ambigüidade ou incerteza na interpretação de um texto, à interpretação favorabilis sobre a odiosa". ${ }^{17}$

A despeito da notoriedade e relevância de NORBERTO BOBBIO, temos que concordar com as objeções exemplares produzidas pelo jurista JUAREZ FREITAS de que o jusfilósofo italiano somente percebe a existência de antinomias no plano das normas. Mesmo quando diante da insuficiência dos critérios cronológicos, hierárquicos e de especialidade, recorre a um quarto modelo que se atém tão-somente à forma da norma. JUAREZ FREITAS afirma que "todas as antinomias são de natureza

16 BOBBIO, Norberto. Ob. cit., p. 98.

17 Idem, ob. cit., p. 98-99. BOBBIO diz que se deve entender por lex favorabilis aquela que concede uma liberdade (ou faculdade, ou direito subjetivo) e por lex odiosa aquela que impõe uma obrigação (seguida por uma sanção). Afirma que não há dúvida e que uma lex permissiva é favorabilis, e uma lex imperativa é odiosa. 
axiológica" 18 e, assim, procura esclarecer que, embora os conflitos se dêem entre normas, "a sua abordagem não pode ficar adstrita a este tipo de incompatibilidade, porque é preciso compreender as antinomias, por igual e destacadamente, no plano axiológico e dos princípios". ${ }^{19}$

Ao vislumbrar-se que as antinomias não são tão-somente um conflito entre normas, mas também um conflito no plano axiológico e principiológico, verifica-se a pertinência do modelo de interpretação sistemática do direito, que permite assim a superação das antinomias ditas como meramente formais. Assim, é de ter-se a compreensão do conceito proposto por FREITAS de que "definem-se as antinomias jurídicas como sendo incompatibilidades possíveis ou instauradas, entre normas, valores ou princípios jurídicos, pertencentes, validamente, ao mesmo sistema jurídico, tendo de ser vencidas para a preservação da unidade interna e coerência do sistema e para que se alcance a efetividade de sua teleologia constitucional". ${ }^{20}$

Interessante ressaltar o proposto por $\mathrm{BOBBIO}$ em relação às antinomias de $2^{\circ}$ grau, ou seja, aquelas que dizem respeito aos conflitos existentes entre os critérios adotados para solver as próprias antinomias. Numa antinomia de $2^{\circ}$ grau em que colide o critério hierárquico com o cronológico, NSA (norma superior anterior) x NIP (norma inferior posterior), deve prevalecer o critério hierárquico. Ocorrendo conflito entre o critério da especialidade com o cronológico, NEA (norma especial anterior) x NGP (norma geral posterior), deve prevalecer o critério da especialidade. Assim, segundo BOBBIO, o critério cronológico é o mais fraco entre eles.

BOBBIO destaca como grande conflito o existente entre os critérios hierárquico e o da especialidade, NSG (norma superior geral) x NIE (norma inferior especial), e diz que "a gravidade do conflito deriva do fato de que estão em jogo dois valores fundamentais de todo ordenamento jurídico, o do respeito da ordem, que exige o respeito da hierarquia e, portanto, do critério da superioridade, e o da justiça, que exige a adaptação gradual do direito às necessidades sociais e, portanto, respeito do critério da especialidade". ${ }^{21}$ Diante de tal conflito, BOBBIO propõe um problema em que colide artigo constitucional com lei especial, "na qual a Corte Constitucional italiana decidiu que o art. $3^{\circ}, \S 3^{\circ}$, da Lei de 22 de dezembro de 1956, relativa à instituição do Ministério das Participações Estatais, que impunha às empresas de forte participação estatal deixarem de fazer parte das organizações sindicais dos outros empregadores, não era incompatível com o art. 39 da Constituição, que concede a qualquer um a liberdade sindical (e, portanto, a liberdade de participar da associação sindical de livre escolha). ${ }^{22}$ A fundamentação que decidiu pelo critério da especialidade foi a exigência de adaptar os princípios gerais de uma constituição às sempre novas situações.

18 FREITAS, Juarez. Ob. cit., p. 59.

19 Idem, ob. cit., p. 58.

20 Idem, ob. cit., p. 62.

21 BOBBIO, Norberto. Ob. cit., p. 109.

22 Idem, ob. cit., p. 109 
O problema proposto por BOBBIO não encontra mistério no magistério do metacritério da hierarquização axiológica, o qual permite solução adequada ao conflito existente. Tomando por base o problema acima, podemos verificar a existência de uma NSG (norma superior geral) que é o artigo constitucional colidindo com lei especial NIE (norma inferior especial). Em tal situação deveria prevalecer o critério hierárquico, norma superior (Constituição) sobre norma inferior (lei especial). O que deve ter ocorrido, e que não é relatado por BOBBIO, é que o princípio geral inserido na Constituição possui igualmente limites, os quais são dados pelos valores superiores inseridos na própria Carta. Assim, há de presumir-se que a lei especial tenha incorporado tais valores, revestindo-se, portanto, de um princípio superior.

JUAREZ FREITAS, em sua exposição de configurações hipotéticas de antinomias jurídicas, estabelece que num conflito entre NSG (norma superior geral) $\mathrm{x}$ NIE (norma inferior especial), "há de prevalecer a NSG, em face do respeito à hierarquia, mesmo diante da especialidade". ${ }^{23}$ Em relação ao problema acima, poderia parecer que se tivesse dado solução contraditória. Tal situação não ocorre, porque aqui se fala tão-somente do critério hierárquico x critério da especialidade, sendo que, ao ser aplicado o metacritério da hierarquização axiológica, o primeiro deve prevalecer sobre o segundo, em razão da própria superioridade que se deve dar ao critério que visa a impor unidade e coerência ao sistema. No entanto, o metacritério da hierarquização axiológica pode fazer com que uma norma inferior especial se sobreponha a uma norma superior geral. Isso ocorre porque o que está sendo hierarquizado não são simplesmente duas normas, mas princípios e valores.

Através da configuração hipotética abaixo, melhor pode-se compreender o afirmado pelo jurista JUAREZ FREITAS ao utilizar o metacritério da hierarquização axiológica. No caso de PS (princípio superior) x NSG (norma superior geral), a prevalência é do PS sobre a NSG em razão de que hierarquicamente o primeiro é superior ao segundo em termos axiológicos. Assim, pode-se concluir que o PS (princípio superior) possa estar inserido em uma NIE (norma inferior especial). FREITAS diz que "sempre prepondera o critério de hierarquização axiológica, mesmo no conflito entre princípios, sendo que, longe de contestá-la, robustece esta posição o fato de que, eventualmente, uma lei especial pode até preponderar à primeira vista, sobre uma norma superior, conquanto, na realidade, tenha sido dada a primazia ao comando principiológico superior da unidade ou da concordância prática, ou outro, dependendo do caso concreto". ${ }^{24}$

Em relação a configuração hipotética em que se tem:

- NS (norma superior) x PS (princípio superior)

ou 


\section{- PS (princípio superior) x PS (princípio superior)}

A colisão acima apresentada não é certamente a mais desejável, no entanto, há de se verificar que, em se tratando de Constituição, esta não é completa e perfeita. No entanto, por essa razão, não se poderá de imediato declarar a inconstitucionalidade de qualquer das normas. Primeiro, porque os princípios são conjuntos de valores que possuem uma certa densidade. Através da hierarquização axiológica, poderá verificarse a preponderância de um princípio sobre o outro, em razão de um ser mais elevado e fundamental do que o outro. Assim, é de afirmar-se "que se considera a hierarquia mais do ponto de vista substancial ou axiológico, consoante o qual sempre há hierarquização possível, em face da completabilidade potencial do sistema jurídico". ${ }^{25}$

\section{LACUNAS DO DIREITO}

O fenômeno lacuna não ocorre no sistema jurídico considerado como um todo ordenado, fechado e completo, em que a ordem normativa delimita o campo da experiência. Nesse modelo de sistema, como para KELSEN, o problema das lacunas ficaria resolvido, porque há uma norma que diz que tudo o que não é juridicamente proibido está permitido, ou seja, qualificando como permitido tudo aquilo que não é obrigatório, nem proibido.

O problema das lacunas ocorre em razão de que o sistema jurídico não é completo, ou seja, falta-lhe completude. NORBERTO BOBBIO diz que "por completude entendese a propriedade pela qual um ordenamento jurídico tem uma norma para regular qualquer caso". ${ }^{26}$ Assim, poder-se-ia dizer que a incompletude significa a existência de lacunas. Lógico que essa proposição é mais complexa que a exposta por BOBBIO, a de que "completude significa falta de lacunas". ${ }^{27}$

Ao ter-se claro que o sistema jurídico não é completo, não quer dizer que ele esteja repleto de lacunas, mas, sim, de que essas possam ser plenamente completadas. Igualmente não se afirma que a plena capacidade de se completar as lacunas quer dizer que o sistema seja subjetivamente completo, mas, sim, objetivamente completável, o que de certa forma propicia dinamicidade do próprio sistema. Superando o entendimento de sistema jurídico fechado, algumas teorias procuraram explicar a ocorrência de lacunas. BOBBIO informa que KARL BERGBOHOM, no livro Jurisprudenz un Rechtsphilosphie, de 1892 (Jurisprudência e filosofia do direito), fez o primeiro enunciado do que foi chamado de "espaço jurídico vazio". ${ }^{28}$ A proposta era de que o homem tinha uma esfera de sua vida que era regulada pelo sistema jurídico e outra em que este sistema não tinha incidência, sendo irrelevante juridicamente. Este espaço, no

25 Idem, ob. cit., p. 76.

26 BOBBIO, Norberto. Ob. cit., p. 115.

27 Idem, ob. cit., p. 115.

28 Idem, ob. cit., p. 128 
qual não incide o direito, é de plena liberdade para o homem, sendo então chamado de espaço jurídico vazio. Tal proposta não suportou as críticas, uma vez que não se poderia admitir como irrelevante a própria liberdade, ou de que tenha espaço que seja indiferente ao sistema jurídico.

A segunda teoria apresentada por BOBBIO é a que trata da norma geral exclusiva, sustentada por E. ZITELMANN no ensaio intitulado "As lacunas no direito". Diz que "todos os comportamentos não compreendidos na norma particular são regulados por uma norma geral exclusiva, isto é, pela regra que exclui (por isso é exclusiva) todos os comportamentos (por isso é geral) que não sejam aqueles previstos pela norma particular". ${ }^{29}$ Muito embora a existência da norma geral exclusiva, que, na falta de previsão de norma particular inclusiva, venha suprir eventual lacuna, não foi suficiente para a superação dos problemas que teimavam em surgir.

O fato de que a norma geral exclusiva não possa suprir todas as lacunas é que junto com a norma particular também tem a norma geral inclusiva, que é geral como a primeira e inclusiva como a segunda. Para BOBBIO, "Chamamos de norma geral inclusiva, segundo a qual, no caso de lacuna, o juiz deve recorrer às normas que regulam casos parecidos ou matérias análogas". ${ }^{30}$ Enquanto a norma geral exclusiva regula de maneira oposta todos os casos não compreendidos pela norma particular, a norma geral inclusiva regula os casos não compreendidos na norma particular de maneira idêntica à sua.

A existência da norma geral exclusiva e da norma geral inclusiva, ambas com possibilidades de opções ao intérprete que procura solver as lacunas existentes em uma norma particular, traz para BOBBIO a verdadeira definição de lacunas no direito, ou seja, "a lacuna se verifica não mais por falta de uma norma expressa pela regulamentação de um determinado caso, mas pela falta de um critério para a escolha de qual das duas regras gerais, a exclusiva ou a inclusiva, deva ser aplicada". ${ }^{31}$

A falta de solução para as lacunas de segundo grau, ou seja, que são basicamente de critérios, tem, através do metacritério da hierarquização axiológica, o caminho que intérprete pode percorrer ao encontro da solução adequada. No caso de uma norma particular, ocorrendo a existência de lacunas, e vendo-se o intérprete diante da antinomia entre a norma inclusiva e a exclusiva, deve este, com base na hierarquização axiológica, verificar a possibilidade da aplicação da norma geral inclusiva ao caso concreto, recorrendo assim à analogia, aos costumes e aos princípios gerais do direito. Não sendo aplicável a norma geral inclusiva, como base na hierarquização axiológica, deve optar o intérprete pela norma geral exclusiva.

Verificamos, assim, que o metacritério da hierarquização axiológica apresenta uma superioridade em relação aos critérios da norma geral exclusiva e inclusiva, o que permite ao hermeneuta dissipar uma eventual antinomia de lacunas em que os critérios

29 BOBBIO, Norberto. Ob. cit., p. 133.

30 Idem, ob. cit., p. 135.

31 Idem, ob. cit., p. 137. 
estejam ao mero arbítrio do intérprete. Nesse sentido, JUAREZ FREITAS afirma "que não deve haver incompletabilidade sistêmica em face das lacunas, exatamente porquanto se hierarquizou, como pressuposto ínsito à idéia mesma de sistema, que a completabilidade é um valor a ser preservado, inclusive para a garantia de outro valor fundamental, qual seja, o da coerência de um sistema que se pretenda capaz de oferecer, para todas as ocasiões, um comando que evite a falta de critérios jurídicos de decisão, impedindo a instauração da irracionalidade arbitrária". ${ }^{32}$

\section{CONSIDERAÇÕES FINAIS}

Não é possível apresentar-se uma conclusão que possa estabelecer a obtenção de uma teoria ou um conjunto de propostas que sejam a fórmula para a solução de todos os problemas que envolvem a complexidade do direito. No entanto, é possível vislumbrar através dos textos analisados o esforço que os juristas engendram para que possam atingir tais objetivos.

Assim, a tentativa de compreensão do direito a partir do ordenamento jurídico e não especificamente através da norma nos permite avançar na solução de conflitos de normas, seja em função de sua antinomia ou de suas lacunas, sem que o sistema seja profundamente abalado. Nesse sentido, a idéia de reafirmar o ordenamento jurídico como um sistema jurídico aberto, com unidade interior, coerente e completável nos permite concluir que o sistema jurídico tem condições de abarcar todo o universo de sua representação. Isto é, nada fica de fora do sistema, de tal forma que ele abrange a todos que compõem uma dada sociedade. Por ser aberto e completável, demonstra toda a sua dinamicidade na condução da ordem jurídica.

\section{REFERÊNCIAS BIBLIOGRÁFICAS}

BOBBIO, Norberto. Teoria do ordenamento jurídico. Trad. Cláudio de Cicco e Maria Santos. Brasília: Universidade de Brasília, 1994.

. Direito e estado no pensamento de Emanuel Kant. Trad. Alfredo Fait. Brasília: Universidade de Brasília, 1995.

CANARIS, Claus-Wilhelm. Pensamento sistemático e conceito de sistema na ciência do direito. Lisboa: Fundação Calouste Gulbenkian, 1996.

DINIZ, Maria Helena. Compêndio de introdução a ciência do direito. São Paulo: Saraiva, 1995.

FREITAS, Juarez. A interpretação sistemática do direito. São Paulo: Malheiros, 1995.

GRUPPI, Luciano. Tudo começou com Maquiavel. Porto Alegre: LPM, 1998.

KELSEN, Hans. Teoria pura do direito. Trad. João Baptista de Machado. São Paulo: Martins Fontes, 1995. Fontes, 1997.

Teoria geral do direito e do estado. Trad. Luis Carlos Borges. São Paulo: Martins

LARENZ, Karl. Metodologia da ciência do direito. Trad. José Lamego. Lisboa: Fundação Calouste Gulbenkian, 1989. 